\title{
Analysis of hydrogen expansion's potential for fuel cell electric vehicle's efficiency
}

\author{
Nicolas Muck \\ German Aerospace Center (DLR) \\ Institute of Vehicle Concepts \\ Vehicle Energy Concepts \\ Stuttgart 70569, Germany \\ Email: Nicolas.Muck@dlr.de
}

\author{
Steffen Wieser \\ German Aerospace Center (DLR) \\ Institute of Vehicle Concepts \\ Vehicle Energy Concepts \\ Stuttgart 70569, Germany \\ Email: Steffen.Wieser@dlr.de
}

\begin{abstract}
This paper investigates the potential of energetic utilization of hydrogen expansion in a fuel cell electric passenger vehicle. The expansion process is considered and evaluated from the thermodynamic side with different assumptions. The theoretical calculations are used in combination with measured data from a research fuel cell electric vehicle to calculate potential energies that are generatable with hydrogen expansion during driving. In addition, the requirements and boundary conditions for a hydrogen expander are considered and different expansion technologies are compared for their suitability for the application in a fuel cell vehicle. Finally, first results of a model of the hydrogen expansion engine in DYMOLA will be presented.
\end{abstract}

Keywords: hydrogen expansion; isentropic expansion work; isothermal expansion work; piston engine; expander technology; fuel cell electric vehicle; high pressure hydrogen; simulation; Dymola; Modelica

\section{INTRODUCTION}

In fuel cell electric vehicles (FCEV), the gaseous hydrogen is carried in pressure tanks at up to 700 bar due to the energy density as well as the limited space available in the vehicle $[1,15]$. Before refueling or driving, the hydrogen must be compressed for this purpose, which requires about $15 \%$ of its calorific value in energy [5]. However, in the fuel cell, which splits the hydrogen and converts it into electricity by reacting with oxygen, pressures of only 1-3 bar are required [12]. Current vehicles use simple pressure reducers with cross-section changes for this purpose to reduce the hydrogen to required operating pressures. In that case no work is currently extracted from this high-energy expansion process, so its enormous potential for energy recovery remains unused and the additional generated energy is not available to the vehicle. Technical prerequisites for utilizing this energy potential are provided by expansion machines. Their use improves both, the overall energy consideration of the fuel cell vehicle (well-to-wheel) and the system efficiency of the powertrain.

The expansion engine which converts the pressure energy of the hydrogen into kinetic energy, is complemented by a generator, which converts the kinetic energy into electric energy. Connected power electronics with voltage converter provides for supplying the electrical energy into the battery or the electric motor. The battery allows the recuperation energy to be stored and supports the fuel cell system during acceleration phases of the vehicle. This means that the stack is less stressed by rapid load changes. The configuration of the powertrain components is shown in Figure 1.

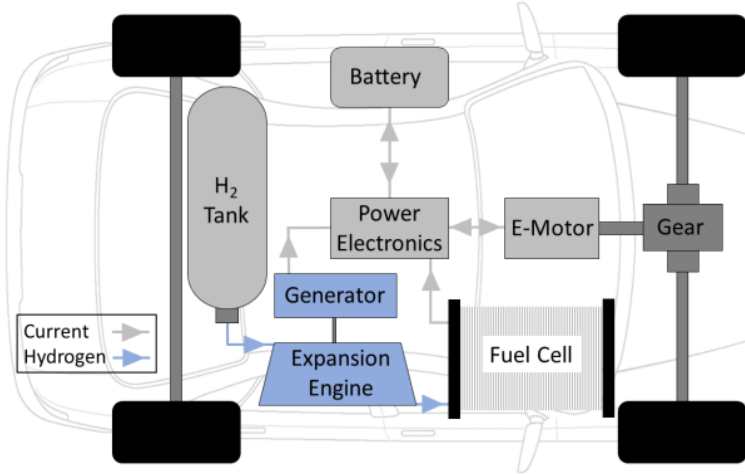

Fig. 1: Components of the FCEV drive train with integrated expansion engine subsystem

The expansion engine generator system is integrated in the hydrogen-carrying connection between the pressure tank and the fuel cell. Depending on the output of the fuel cell, the generator thus provides additional energy for propulsion or supplying auxiliary consumers. Even small amounts of power are of great importance in mobile applications. Increased efficiency in turn has a positive effect on the range of FCEV.

The paper deals with the potential analysis and quantification of the amount of energy gained from hydrogen expansion in the vehicle, both from the point of view of thermodynamics and in the overall system of a 
FCEV. Based on this and the additional boundary conditions of the system, the selection of the most suitable type of expansion engine for vehicle use is also made. From the selected configuration, potential range increases of the vehicle are calculated based on constant speeds, driving cycles and drives with complete tank emptying. The weight of the system and the resulting energy balance, which must be carried in the vehicle, are also considered.

The FCEV Hyundai Nexo serves as the reference vehicle for all investigations, which was measured on the DLR Institute of Vehicle Concepts' climatic roller test bench regarding its performance and hydrogen consumption.

\section{THERMODYNAMICS OF EXPANSION PROCESS}

The following chapter contains the thermodynamic consideration of the hydrogen expansion process.

If hydrogen is considered at high pressures, the ideal gas law no longer provides the required accuracy and real gas equations must be used. The density deviations between ideal and real gas at room temperature are given in Figure 2. Above pressures of 100 bar the deviation become clearly visible and real gas equations are needed. The deviation are caused by intermolecular forces of attraction and repulsion, which are not considered in the ideal gas modeling. For this reason, real gas equations for hydrogen according to Leachman [8] were used for the evaluations in this paper. These are currently the most precise equations of state for hydrogen and were evaluated using the open-source tool CoolProp in SciLab.

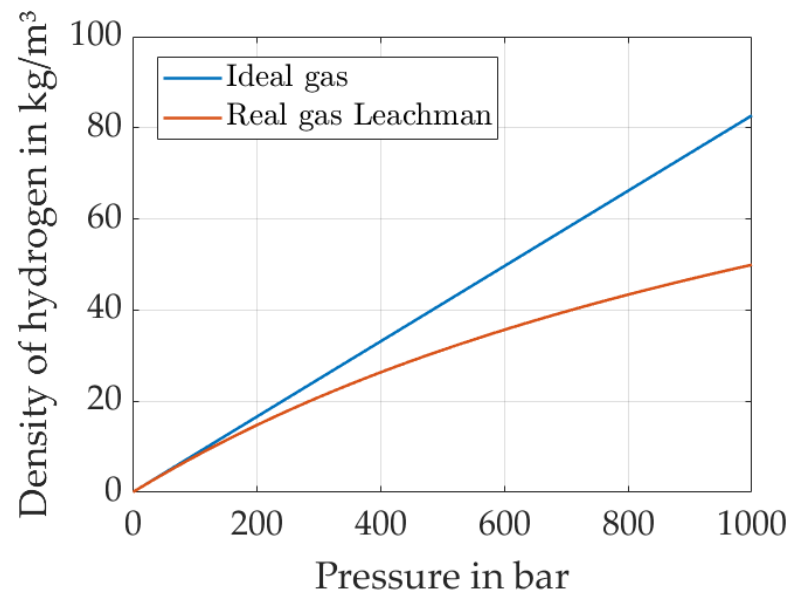

Fig. 2: Hydrogen equations of state, comparison of ideal and real gas modeling

For the expansion process, different theoretical approaches are available in the literature [13]. These are the isenthalpic, isothermal and isentropic expansion. To enable the theoretical calculation, the variable specific enthalpy $h$, temperature $T$ or specific entropy $s$ is kept constant over the process. The three processes are shown in Figure 3 in the T-s diagram of hydrogen. It is noticeable that in isenthalpic expansion the temperature increases over the expansion process. This is related to the Joule-Thomson effect, which describes the temperature change due to an isenthalpic pressure change and is quantified by the Joule-Thomson coefficient. For hydrogen in the relevant expansion range ( 1 bar to 700 bar), the Joule-Thomson coefficient is negative, so that temperature and pressure change in opposite directions. Consequently, a decreasing pressure results in an increasing temperature. However, the assumption of isenthalpic throttling must be taken into account. This means that the gas does no work and is free to expand. However, with the hydrogen expansion studied in this paper, work is to be done so that the isenthalpic process and the Joule-Thomson effect do not play any further role. Instead, the isothermal and isentropic expansions demonstrate processes in which the gas performs work. The isothermal process represents the equivalent of a very slow expansion process in that the temperature remains constant due to maximum heat transfer from the environment. However, hydrogen expansion in the fuel cell vehicle will have to proceed rapidly due to load dynamics. Accordingly, isentropic expansion is the most relevant case for the process considered here. In this case, work is performed by the gas and no heat is exchanged with the environment. Accordingly, very low hydrogen temperatures of less than $100 \mathrm{~K}$ can occur in the isentropic process.

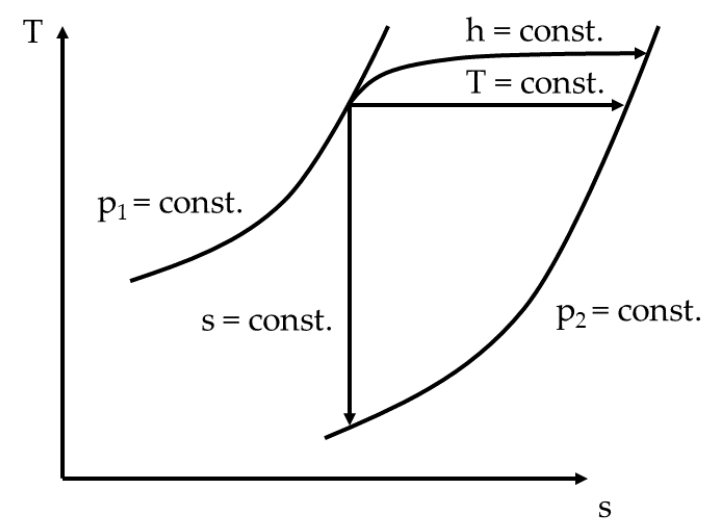

Fig. 3: Specific volume work of hydrogen expansion in the isentropic and isothermal process

The corresponding values of the work of volume change to a final pressure of 3 bar are shown in Figure 4. The isentropic work is calculated via enthalpy difference, while the isothermal work is calculated via enthalpy difference in combination with reversible heat. The maximum possible work is calculated via pressure difference from 700 bar to 30 bar. The specific energy in the isentropic process is $3.61 \mathrm{MJ} / \mathrm{kg}$ and that of the isothermal process is $7.13 \mathrm{MJ} / \mathrm{kg}$ (see Figure 4 and Table 1). 


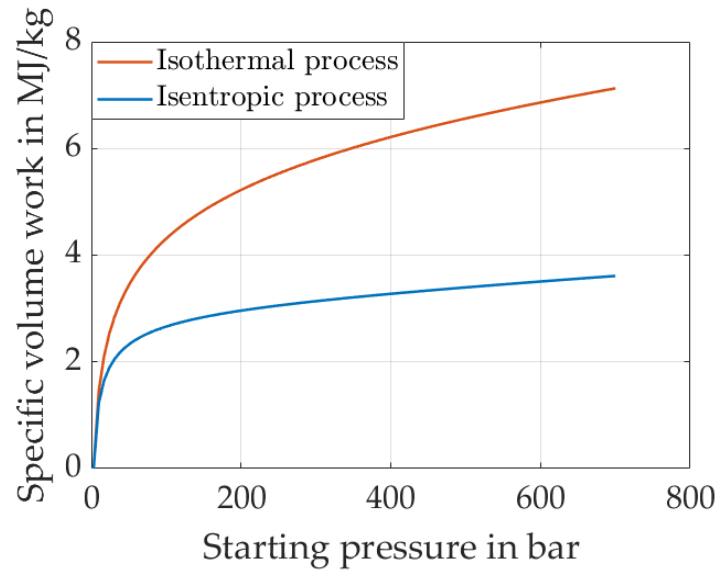

Fig. 4: Specific volume work of hydrogen expansion in the isentropic and isothermal process to an end pressure of 3 bar and $20{ }^{\circ} \mathrm{C}$

Table 1 also shows that a change in the final pressure has a greater effect on the specific energy than a change in the initial pressure. In the isentropic case, the same work is done when expanding from $100 \mathrm{bar}$ to $3 \mathrm{bar}$ as from 700 bar to 52 bar although the difference of the initial pressures is significantly larger than that of the final pressures. An optimization of the work in the expansion process should therefore focus on a maximum reduction of the final pressure.

TABLE 1: ISENTROPIC AND ISOTHERMAL EXPANSION WORK OF HYDROGEN

\begin{tabular}{|c|c|c|c|}
\hline \multicolumn{2}{|c|}{$\begin{array}{c}\text { Pressure } \\
\text { in bar }\end{array}$} & \multicolumn{2}{c|}{$\begin{array}{c}\text { Expansion work in } \\
\text { MJ/kg }\end{array}$} \\
\hline $\mathrm{p}_{1}$ & $\mathrm{p}_{2}$ & Isentropic & Isothermal \\
\hline 700 & 3 & 3.61 & 7.13 \\
\hline 100 & 3 & 2.66 & 4.31 \\
\hline 700 & 52 & 2.66 & 3.64 \\
\hline 100 & 52 & 0.75 & 0.83 \\
\hline
\end{tabular}

\section{METHODICAL APPROACH}

This section deals with the identification and definition of boundary conditions and prerequisite for calculations of the amount of energy generated from the expansion process of compressed hydrogen.

In section two, the process was considered from a thermodynamic point of view. The most important parameters for the energetic consideration, which were derived from this section, are the hydrogen mass flow, the inlet and outlet pressure, the resulting pressure ratio, the surrounding temperature as well as the differences in the specific enthalpy and entropy. All these parameters are necessary to calculate the occurring expansion work.
Reasonable design and selection of the expansion engine can only be made if the physical inlet and outlet variables are known. This includes the possible pressure differences and ratios from inlet to outlet, which must be reduced in an efficient manner. In addition, the absolute pressure and the maximum and minimum mass flows are considered. This results in the existing volume flows in the system via hydrogen pressure and temperature.

In order to be able to quantify these boundary conditions with regard to the technical system design in this early phase of research, it is important to define a reference system for application. The FCEV Hyundai Nexo, a research vehicle of the Institute of Vehicle Concepts of the German Aerospace Center (DLR), is used as a reference vehicle. In the Nexo, starting from the three hydrogen tanks, after the respective closure valves, the tanks are combined in a hydrogen distribution station. All pressurized tanks are thus located in the underbody around the rear axle of the car and are emptied evenly during operation so that the pressure in all tanks is always at the same level. The minimum pressure of the tanks in operation is 40 bar, as deep discharge reduces the service life of pressure tanks. The problem with this is material fatigue due to load changes at different pressures. The tanks in the Hyundai Nexo have a service life of 5000 charging cycles, where a charging cycle is seen as an increase in pressure in the tank of over 175 bar. After the hydrogen tank pipes are joined, a pressure reducer is connected, which reduces the hydrogen from the maximum 700 bar to 17-22 bar, see Figure 5 .

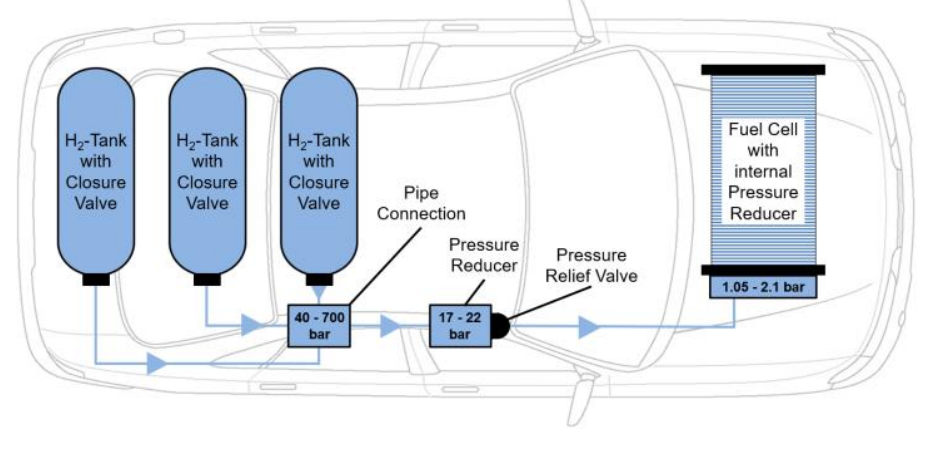

Fig. 5: Hydrogen-connecting components of FCEV's drive train

Behind the pressure reducer is a pressure relief valve which releases the hydrogen as soon as it exceeds 22 bar. At 17-22 bar, the hydrogen reaches the stack, where it is reduced to an operating pressure of 1.05-2.1 bar within the stack. With known mass flows, the flow velocity or the volume flow in the pipes can be determined via the internal diameters of the hydrogen-carrying connecting pipes. These are required for the selection and design as 
well as calculation of the expansion engine and energy quantity.

To measure the relevant parameters under defined load profiles, DLR installed a large number of additional sensors and measuring equipment in the reference vehicle. Combined with the series-installed sensors from Hyundai, which can be read out via OBD connector, the parameters pressure, temperature of the hydrogen can be recorded at a specified fuel cell output. The temperature sensors are located at the inlet and outlet of the pressure reducer, at the tank valve of the middle and front tanks and at the hydrogen distribution station addressed. The pressure in the tanks can be evaluated via Nexo's OBD system. The voltage and current of the battery and fuel cell can also be measured individually and thus, by multiplying the aforementioned variables, the power can also be measured. Most of the comparative data collected was recorded on the air-conditioned roller test bench at the DLR Institute of Vehicle Concepts in Stuttgart, Figure 6.

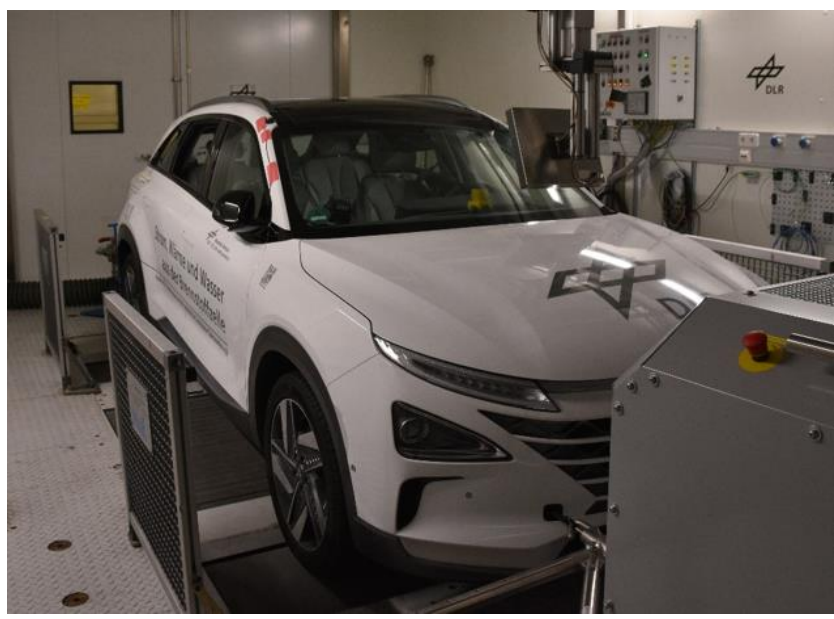

Fig. 6: Parameter measurements of the vehicle on the hydrogen certificated climatic roller test bench

The hydrogen mass flow could not be measured directly by either the sensors installed from Hyundai or the additional integrated sensors from DLR for safety reasons. Thus, the mass flow was measured via the Coriolis sensor of the roller test bench. For this purpose, the hydrogen building supply was connected to the vehicle so that the hydrogen required for the vehicle fuel cell was supplied directly from the institute's stationary hydrogen tube bundle system.

In the current system of the Hyundai Nexo, the hydrogen enters the fuel cell at 22-17 bar. This value thus represents the range of outlet pressure of the expansion engine. However, the pressure in the stack is reduced to 2.1-1.05 bar. These values represent a theoretically thermodynamically lowest outlet pressure. This must be considered when restructuring the system. The highest possible pressure ratio in the current configuration of the Hyundai Nexo is therefore 41.18 compared to the lowest possible, with a quasi-empty tank at 1.82. Using the theoretical outlet pressures of the fuel cell, theoretical pressure ratios of 666.66 at the maximum and 19.05 at the minimum are calculated. The mentioned pressures and pressure ratios are summarized in Table 2 . The inlet temperature is considered to be the ambient temperature, while the outlet temperature is variable and dependents on the process path.

TABLE 2: MEASURED PARAMETERS OF THE REFERENCE VEHICLE

\begin{tabular}{|l|l|l|}
\hline Inlet pressure & bar & $700-40$ \\
\hline Outlet pressure & $\mathrm{bar}$ & $22-17$ \\
\hline Outlet pressure (theo.) & $\mathrm{bar}$ & $2.1-1.05$ \\
\hline Pressure ratio & $\mathrm{p}_{1} / \mathrm{p}_{2}$ & $41.18-1.82$ \\
\hline Pressure ratio (theo.) & $\mathrm{p}_{1} / \mathrm{p}_{2}$ & $666.67-19.05$ \\
\hline & $\mathrm{g}$ & \\
\hline Maximum mass flow & $\mathrm{g} / \mathrm{s}$ & 1.55 \\
\hline Average mass flow (175 km/h) & $\mathrm{g} / \mathrm{s}$ & 1.4 \\
\hline Average mass flow (WLTC) & $\mathrm{g} / \mathrm{s}$ & 0.124 \\
\hline Volume flow Inlet & $1 / \mathrm{min}$ & $28.1-2.3$ \\
\hline Volume flow Outlet & $1 / \mathrm{min}$ & $65.1-50.5$ \\
\hline Volume flow Outlet (theo.) & $1 / \mathrm{min}$ & $1040-522$ \\
\hline
\end{tabular}

The mass flow is the starting point for the power calculation and reaches its maximum value during acceleration to the maximum constant speed on the roller test bench measured at $175 \mathrm{~km} / \mathrm{h}$. The measured associated mass flow is $1.55 \mathrm{~g} / \mathrm{s}$ at the peak. The averaged value at this speed is approximately $1.4 \mathrm{~g} / \mathrm{s}$. Compared with average consumptions given in Table 2, the consumption of $0.95 \mathrm{~kg} / 100 \mathrm{~km}$ given by the WLTC at average speed of $47 \mathrm{~km} / \mathrm{h}$ results in a mass flow of $0.124 \mathrm{~g} / \mathrm{s}$. Based on denseties of $40.4 \mathrm{~kg} / \mathrm{m}^{3}$ (700 bar) respectivley $3.31 \mathrm{~kg} / \mathrm{m}^{3}$ (40 bar) at $12.5^{\circ} \mathrm{C}$, the maximum mass flow and the inlet pressures of 700 bar and $40 \mathrm{bar}$, the volume flow at the inlet is calculated to be $2.3 \mathrm{l} / \mathrm{min}$ and $28.1 \mathrm{l} / \mathrm{min}$. The outlet volume flow rate strongly dependents on the outlet temperature, which cannot be determined by the boundary conditions. If the maximum of the outlet volume flow is considered and an isothermal process is assumed, volume flows of $65.1-50.51 / \mathrm{min}$ or, with the theoretical outlet pressures of 2.1-1.05 bar, volume flows of $1040-522 \mathrm{l} / \mathrm{min}$ in total are shown. The underlying calculations were performed according to the Leachman equation of state in SciLab, as described earlier. Here, the decreasing pressure in the tank due to 
the decreasing amount of hydrogen was also taken into account.

\section{EXPANSION TECHNOLOGIES}

The following chapter contains the expansion technologies.

The expansion engine must meet various technical requirements in order to be integrated into the powertrain of an FCEV. In addition to criteria that are mainly defined by vehicle application and system efficiency (weight, packaging, efficiency, reliability, temperature distribution, maintenance options, etc.), hydrogen purity is a criterion that is indispensable for the fuel cell. Compared to the system without expansion engine, the hydrogen must not be changed in its composition even with expansion engine. The hydrogen grade (purity) considered for the use in a typical automotive fuel cell is $99.995 \%$ with the following contamination limits $[16,17]$ :

$\begin{array}{lll}\text { - } & \mathrm{CO} & \leq 0.2 \mu \mathrm{mol} / \mathrm{mol} \\ \text { - } & \text { Sulfur } & \leq 0.004 \mu \mathrm{mol} / \mathrm{mol} \\ \text { - } & \text { Hydrocarbons } & \leq 2 \mu \mathrm{mol} / \mathrm{mol}\end{array}$

Due to the sensitivity of the fuel cell to hydrocarbons, the oil- and grease-free lubrication of various subcomponents, such as the bearings in the expansion engine, must be regarded as a particular requirement. Oilfree concepts such as air or magnetic bearings are an exclusion criterion here.

Using hydrogen technically in an expansion engine without chemically modifying the hydrogen has not yet been considered scientifically or industrially. Thus, for the analysis and selection suitable comparison concepts must be used that completely or at least partially fulfill the same function. These are divided in two categories. On the one hand hydrogen compressors and on the other hand systems that use pressure differences in gases to power various systems or energy conversion. The hydrogen compressors must technologically meet the same criteria such as tightness and resistance to high pressures. The use of compressed gas in comparative processes represents the same function, since the energy from the expansion is used, albeit with different process gases.

\section{A. Hydrogen compressors}

Hydrogen compressors are used in various applications. One application currently in high demand is compressors for hydrogen filling stations. In Germany, the technology of the ionic compressor is leading. About half of the German hydrogen filling stations use it to compress the hydrogen [3]. Two ionic compressors are installed, which compress the hydrogen in 5 stages to 900 bar. In another $30 \%$, hydrogen compressors are piston engines. The pistons compress up to $900 \mathrm{bar}$, because during the refueling process a pressure drop is still required compared to the 700 bar that is to be generated in the tank [9]. The mass flows that are converted at refueling stations are significantly greater than those that needed in fuel cell vehicles. Comparable compressor technology for these mass flows already exists on the market. Accordingly, a sufficient number of available and established concepts for the compression of hydrogen in the desired pressure ranges of the application as an expansion engine exist.

\section{B. Compressed gas utilization}

Applications for compressed gas exist primarily in form of compressed air in pneumatics. The maximum pressure here is usually less than 16 bar and vane motors are often used [2]. Compressed gas in vehicle technology has also been investigated as an idea for propulsion. There have been approaches to modeling concepts as in and compressed air powered passenger cars $[6,10]$. However, all research and development activities in this area were discontinued again due to insurmountable technical problems that were not described in detail. Further approaches to pneumatic vehicles can be found in the research partly also called "Pneumobil" [11].

When considering flow engines in form of radial and axial turbines, it becomes apparent that these only become relevant for applications at significantly higher volume flows. When designed for the boundary conditions mentioned, the cross-sections drop to such an extent that manufacturing problems and enormously high speeds occur, which stress the bearings. In addition, the defined geometry of the turbo engine offers less flexibility for fluctuating mass flows during operation. They only dissipate low pressure ratios per stage, which is why a large number of stages with correspondingly high installation space requirements are required [4]. The key requirement preventing application is thus efficiency at high pressure ratios. According to our research, there are no known applications of turbo engines for hydrogen. The application is shown in Figure 7 and make sense only from volume flows of about $500 \mathrm{Nm}^{3} / \mathrm{h}(=12.5 \mathrm{~g} / \mathrm{s})$ and only in the lower pressure range of less than $100 \mathrm{bar}$. The high-pressure part of the expansion can thus not be used. The compressors are considered because no comparable literature exists on expansion technology. 


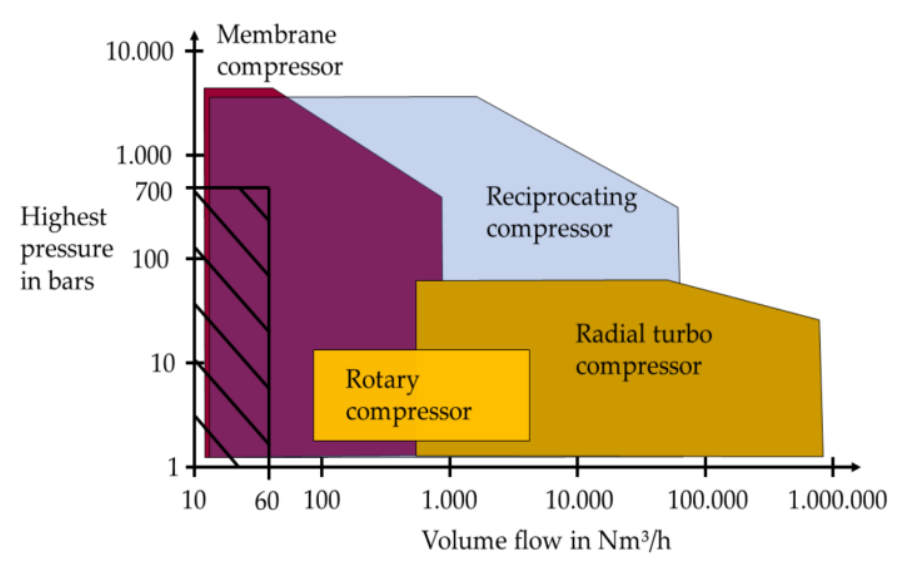

Fig. 7: Comparison of different hydrogen compressor concepts [19]

Regarding Figure 7, the vane motor belongs to rotary compressors and is only to be used at low absolute pressures of less than 20 bar. Otherwise too much leakage occurs inside at the vanes, which reduces the efficiency. If pressures below 20 bar are relieved, an application is conceivable.

The ionic compressor is a supplement to the reciprocating piston concept, but cannot be given a final assessment because it is only used for larger mass flows and is a comparatively new technology. In [3], reliability problems were reported, requiring frequent maintenance intervals. Thus, the crucial requirement preventing its application is reliability and the maturity of research.

The reciprocating engine, on the other hand, is seen as the most promising expansion concept. It shows sufficient efficiency even with fluctuating mass flows by variable speed. The resulting pulsation of the gas flow at the outlet of the system can be absorbed by a damping vessel. Sealing is also possible without oil, as demonstrated in dry-running hydrogen compressors that use reciprocating piston concepts. This ensures the purity of the hydrogen and also minimizes losses due to blowby on the piston. Thanks to experience in downsizing internal combustion engines, the installation space can also be used effectively in expansion mode with hydrogen. In terms of reliability, the reciprocating piston concept shows clear advantages compared to the other concepts, due to its widespread use in compressors. It also impresses with its simple basic concept. An extension of the system in form of a membrane expander or in combination with an ionic fluid represent innovative possibilities for the future, but are not yet relevant for the present research stage. A membrane expander can achieve a hermetic seal of the hydrogen and the ionic fluid can improve heat transfer $[7,12]$.

The decision that reciprocating pistons are the favored concept for the fuel cell vehicle application was also confirmed in technical discussions with air motor and compressor manufacturers. The pulsation associated with the reciprocating engine does not pose a problem for the dynamics in the fuel cell vehicle. These are limited by response times of $0.5 \mathrm{~s}$ to $0.7 \mathrm{~s}$ of the air compressor of the fuel cell stack on the cathode side, although the period durations of reciprocating engines are significantly lower than this value [18].

\section{HYDROGEN EXPANSION POWER IN A FUEL CELL ELECTRIC PASSENGER VEHICLE}

The profitable work of the hydrogen expansion is quantified in the following section in combination with measured values from the Hyundai Nexo. In addition, the influence of the system mass of the hydrogen expansion engine on the vehicle power is investigated.

These data are used with the theoretical calculations to determine the potential expansion power in the vehicle. For this purpose, individual constant speeds are evaluated as well as the driving cycle of the WLTC, which represents an average driving behavior. Since no studies have yet been carried out on hydrogen expansion, there are some uncertainties in the evaluation of the power with regard to the thermodynamic assumptions, the efficiency and the pressure difference. These are considered by using different evaluation variants, which are summarized in Table 3. The first evaluation variant represents the absolute theoretical maximum by considering the isothermal process at $100 \%$ efficiency and maximum pressure ratio. The evaluation variant « best case » refers to the isentropic process and a pressure reduction from 700 bar to 2.1 bar. The 700 bar correspond to a completely filled hydrogen tank and the 2.1 bar to the maximum pressure in the fuel cell stack of the Hyundai Nexo. The «best case » variant therefore corresponds to the real maximum of the isentropic process. The last evaluation variant is the "worst case », which corresponds to the minimal power to be expected in reality. In this case, an efficiency of $50 \%$ is assumed, which has been shown to be a relevant estimate from comparisons with hydrogen compressors and compressed air motors. The pressure is reduced from 45 bar to 2.1 bar, which in turn corresponds to the lowest pressure level in the Hyundai Nexo, i.e. an empty pressure tank.

\section{TABLE 3: EVALUATION VARIANTS FOR HYDROGEN EXPANSION}

\begin{tabular}{|c|c|c|c|c|c|}
\hline \multirow{2}{*}{ Name } & \multicolumn{2}{|c|}{$\begin{array}{c}\text { Pressure } \\
\text { in bar }\end{array}$} & Assumption & Efficiency & $\begin{array}{c}\text { Expansion } \\
\text { work in } \\
\text { MJ/kg }\end{array}$ \\
\cline { 2 - 3 } & $\mathrm{p}_{1}$ & $\mathrm{p}_{2}$ & & & 7.56 \\
\hline $\begin{array}{c}\text { Theoretical } \\
\text { maximum }\end{array}$ & 700 & 2.1 & Isothermal & 100 & 7.67 \\
\hline Best case & 700 & 2.1 & Isentropic & 100 & 3.22 \\
\hline Worst case & 45 & 2.1 & Isentropic & 50 & 1.22 \\
\hline
\end{tabular}


Various constant speeds were measured on the roller test bench. The corresponding hydrogen mass flow, fuel cell and expansion power according to the different evaluation variants are summarized in Table 4. The proportion of the expansion in the fuel cell power is in parentheses.

\section{TABLE 4: EXPANSION POWER AT DIFFERENT VEHICLE SPEEDS}

\begin{tabular}{|c|c|c|c|c|c|}
\hline \multirow{2}{*}{$\begin{array}{l}\text { Vehicle } \\
\text { speed } \\
\text { in } \mathrm{km} / \mathrm{h}\end{array}$} & \multirow{2}{*}{$\begin{array}{l}\text { Mass } \\
\text { flow in } \\
\mathrm{g} / \mathrm{s}\end{array}$} & \multirow{2}{*}{$\begin{array}{l}\text { Fuel cell } \\
\text { power } \\
\text { in } \mathrm{kW}\end{array}$} & \multicolumn{3}{|c|}{ Expansion power in $\mathrm{kW}$} \\
\hline & & & $\begin{array}{l}\text { Theoretical } \\
\text { maximum }\end{array}$ & $\begin{array}{l}\text { Best } \\
\text { case }\end{array}$ & $\begin{array}{l}\text { Worst } \\
\text { case }\end{array}$ \\
\hline 50 & 0.05 & 3.3 & $\begin{array}{c}0.31 \\
(9.4 \%)\end{array}$ & $\begin{array}{c}0.16 \\
(4.9 \%) \\
\end{array}$ & $\begin{array}{c}0.06 \\
(1.8 \%) \\
\end{array}$ \\
\hline 120 & 0.43 & 31.6 & $\begin{array}{c}3.05 \\
(9.7 \%)\end{array}$ & $\begin{array}{c}1.59 \\
(5.0 \%)\end{array}$ & $\begin{array}{c}0.52 \\
(1,7 \%)\end{array}$ \\
\hline 150 & 0.84 & 57.98 & $\begin{array}{c}5.90 \\
(10.2 \%)\end{array}$ & $\begin{array}{c}3.09 \\
(5.3 \%) \\
\end{array}$ & $\begin{array}{c}1.02 \\
(1,8 \%)\end{array}$ \\
\hline
\end{tabular}

For a classic highway drive at $120 \mathrm{~km} / \mathrm{h}$, an expansion power of $3.05 \mathrm{~kW}$ is possible in the isothermal maximum. The isentropic best case shows a power of $1.59 \mathrm{~kW}$ whereas the worst case still allows a power of $0.52 \mathrm{~kW}$. The partial power of the expansion to the fuel cell shows that in the «best case » about $5 \%$ of the fuel cell power can be compensated by the expansion. The relative proportion increases with vehicle speed due to decreasing fuel cell efficiencies at high power levels. The hydrogen expansion engine therefore offers possibilities to compensate for this decreasing efficiency. The values described in Table 4 are shown in Figure 8 in a bar chart. This again shows the large differences between the various evaluation variants and speeds.

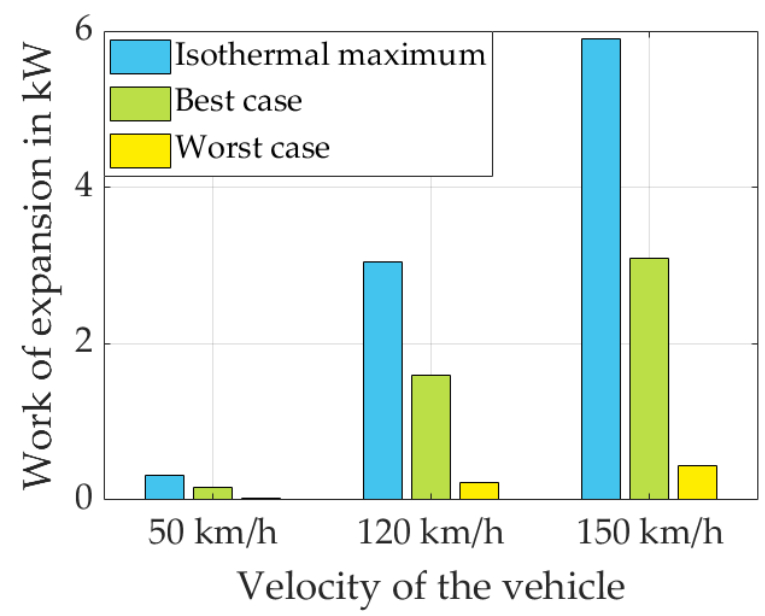

Fig. 8: Hydrogen expansion work in a fuel cell electric passenger car at different velocities and assumptions

So far, only constant speed points have been considered. In order to investigate the expansion power in real driving behavior with load changes and acceleration processes, the WLTC driving cycle is used below. Figure 9 shows the expansion power over the driving cycle for the «best case » and «worst case » of Table 3.
The real power to be expected will occure between these two curves, depending on the assumptions and tank filling. The area between the curves thus symbolizes uncertainty of the current state of research. If these curves are integrated and the possible increase in range is calculated with one tank filling, the «best case» shows an increase of $26.15 \mathrm{~km}(3.5 \%)$ and the « worst case » an increase of $13.07 \mathrm{~km}(1.73 \%)$. The total range of the Hyundai Nexo is stated by the manufacturer at $756 \mathrm{~km}$.

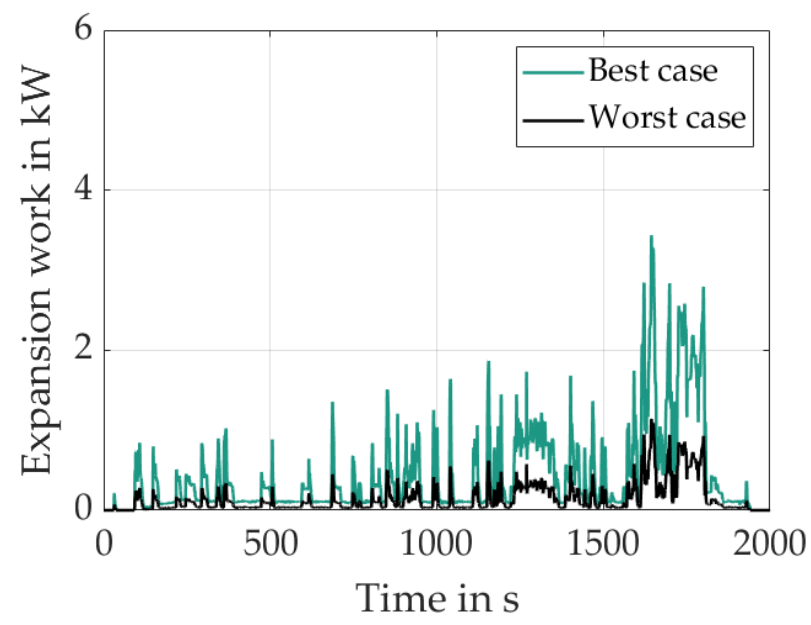

Fig. 9: Hydrogen expansion work of the reference vehicle in a WLTC

In the previous performance calculations of the expansion engine, the weight of the system was not yet evaluated. However, the additional weight results in increased energy consumption of the vehicle. To investigate the influence of the system weight, the driving resistance equation for the Hyundai Nexo was parameterized and evaluated. Constant speeds were selected for this purpose in order to be able to draw a comparison with the measured data from Table 4 . For the weight of the expansion engine, $50 \mathrm{~kg}$ is an appropriate estimation when considering hydrogen compressors, diesel generators as well as other reciprocating systems in similar power classes. In order to present the influence of the weight, the calculations were additionally carried out for a system of $100 \mathrm{~kg}$. The results can be seen in Figure 10. It can be seen that at a system weight of $50 \mathrm{~kg}$, the expansion engine can compensate for the required power from a speed of less than $30 \mathrm{~km} / \mathrm{h}$ in the «best case » and $60 \mathrm{~km} / \mathrm{h}$ in the "worst case », thus increasing the efficiency of the vehicle. Especially at higher speeds, the power to be expended can be compensated many times over by the weight. The influence of the system weight is relatively small, since even with a $100 \mathrm{~kg}$ system, a positive energy balance exists in the «best case » from $52 \mathrm{~km} / \mathrm{h}$ and in the «worst case » from $111 \mathrm{~km} / \mathrm{h}$. The speed values mentioned are subject to the inaccuracy of the linear interpolation between the measuring points. 


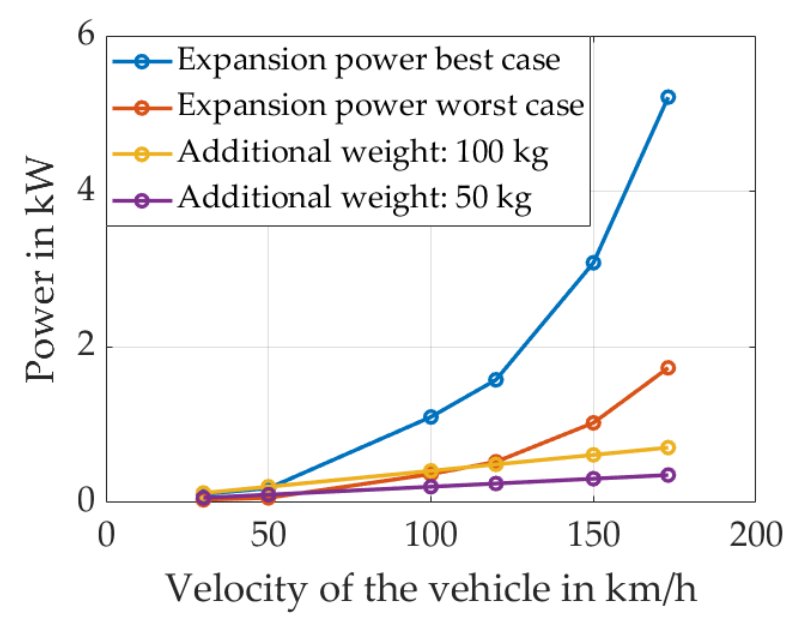

Fig. 10: Hydrogen expansion work in comparison to the power consumed by the additional weight of the expansion engine for different vehicle velocities

\section{FIRST SIMULATION APPROACH AND RESULTS}

The following section shows the selected modeling approach and initial simulation results for the hydrogen expansion engine.

The previous theoretical considerations have shown that there is a further need for a dynamic system analysis in order to quantify the operation of the hydrogen expansion engine in various application cases. For this purpose, a first modeling of the system was created in the commercial modeling and simulation environment DYMOLA, which is based on the programming language Modelica. The model interface is shown in Figure 11. The subcomponents are: intake and exhaust valves, cylinder, piston, crankshaft and a speed controlled load torque representing the alternator. The choice of the reciprocating engine as expansion technology was justified in chapter 4 .

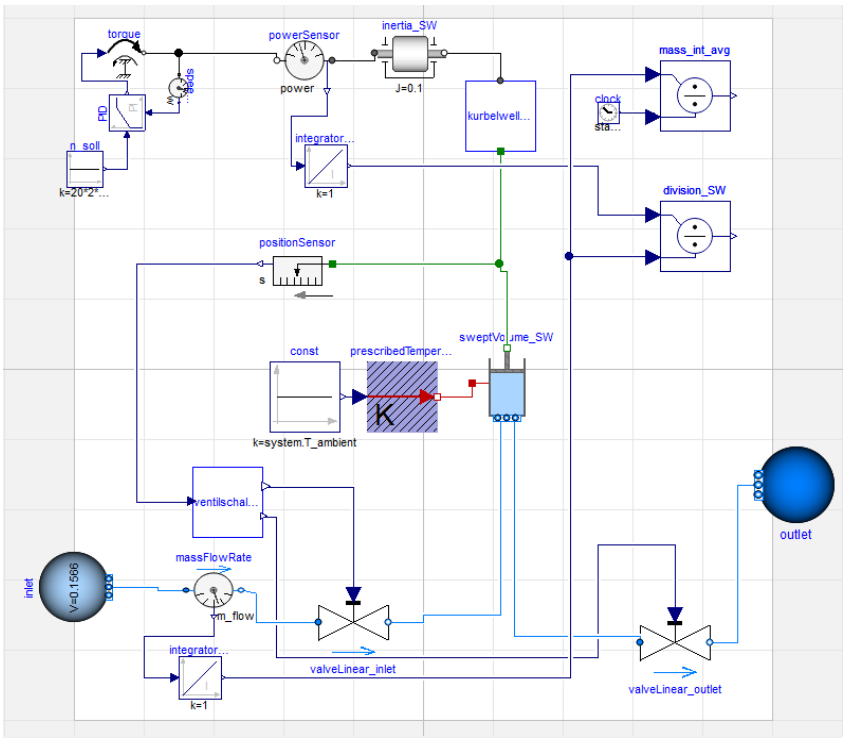

Fig. 11: Surface of the created Dymola model
Figure 12 and Figure 13 show the results of initial simulation runs with constant mass flow. The average mass flow was set to $1.5 \mathrm{~g} / \mathrm{s}$, which corresponds to the maximum mass flow in the Hyundai Nexo. A setpoint of $1200 \mathrm{rpm}$ was selected for the speed in order to provide the necessary dynamics for load changes. Both curves can be seen in Figure 12 with some pulsation due to the opening and closing of the cylinder valves.

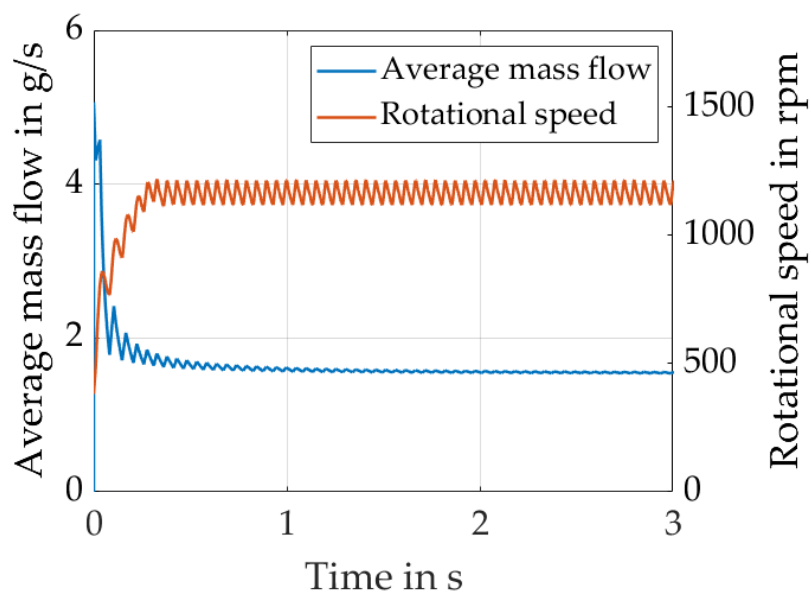

Fig. 12: Result of a simulation run of the hydrogen expansion engine concerning the average mass flow and rotational speed

Figure 13 shows in the same simulation run as Figure 12 the average power as well as the specific expansion energy, which is used to calculate the efficiency. Both curves approach a limit defined by the steady-state hydrogen mass flow. For the expansion power this is $1.4 \mathrm{~kW}$ and the specific expansion energy $0.9 \mathrm{MJ} / \mathrm{kg}$. The calculated isothermal efficiency is only $15 \%$, which is due to high gas exchange losses. The isentropic efficiency could not yet be determined due to the lack of material data. The efficiency shows a high need for optimization in the control system of the hydrogen expansion engine. The influencing parameters for this control are: piston position and speed, valve position, load torque and hydrogen demand of the fuel cell. They must be optimally coordinated in the control system in order to inject the appropriate amount of hydrogen into the cylinder via the controlled valves at each operating point. This will be part of future improvements to the modeling. 


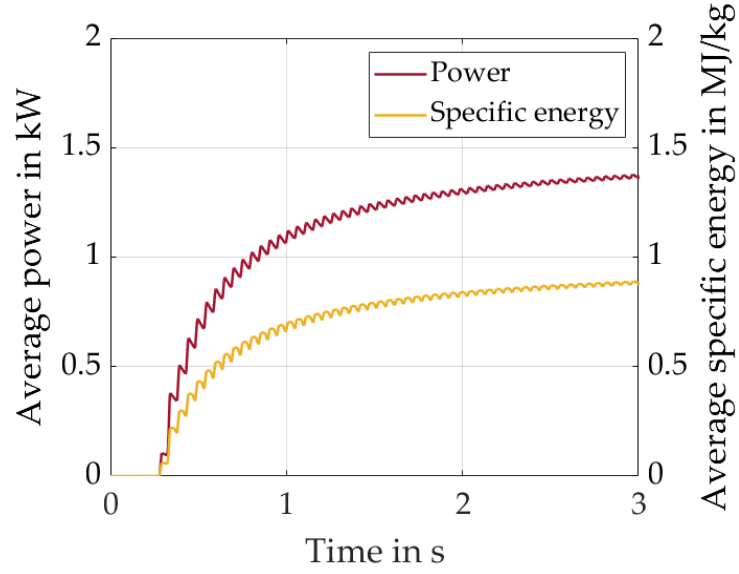

Fig. 13: Result of a simulation run of the hydrogen expansion engine concerning the average power and specific energy

\section{CONCLUSION}

This paper demonstrates the suitability of reciprocating engines as an expansion method for power generation in fuel cell electric vehicles. The range increase to be expected from hydrogen expansion in a passenger car is between $13 \mathrm{~km}$ and $26 \mathrm{~km}$ for a completely filled tank, depending on the assumption. At a vehicle speed of $120 \mathrm{~km} / \mathrm{h}$ the potential of up to $3 \mathrm{~kW}$ expansion power is shown. Considering the dead weight of the expansion engine, the overall energy balance in the fuel cell electric vehicle is still positive, especially at high fuel cell power. From this it can be concluded that for systems with higher power and steady-state operating points, such as fuel cell electric trucks, trains and ships, further areas of application are indicated for the hydrogen expansion engine.

\section{REFERENCES}

[1] N. de Miguel, R. Ortiz Cebolla, B. Acosta, P. Moretto, F. Harskamp, and C. Bonato "Compressed hydrogen tanks for onboard application: Thermal behaviour during cycling" International Journal of Hydrogen Energy, 2014
[2] O. Dumont, A. Parthoens, R. Dickes, and V. Lemort "Experimental investigation and optimal performance assessment of four volumetric expanders (scroll, screw, piston and roots) tested in a small-scale organic Rankine cycle system" in Energy, 2018

[3] Neumann und Esser "The real story of hydrogen compression" Mission Hydrogen presentation, 02.09.2020.

[4] A. B. Galyas, L. Tihanyi, I. Szunyog, and L. Kis "Investigation of pressure regulator replacement by turbo expander in hungarian gas transfer stations" in ActaTecnologia International Scientific Journal about Technologies, 2018.

[5] M. Hirscher "Handbook of Hydrogen Storage", Wiley VCH Verlag GmbH and Co KGaA, 2010

[6] F. Kratschun, J. Köhne, P. Kloft, H. Baum, and K. Schmitz „One dimensional unsteady model of a hydropneumatic piston accumulator based on finite volume method" 12th International Fluid Power Conference in Dresden, 2020

[7] N. A. Kermani and M. Rokni "Heat transfer analysis of liquid piston compressor for hydrogen applications" in International Journal of Hydrogen Energy 40, 2015.

[8] J. W. Leachman, R. T Jacobsen, S. G. Penoncello, and E. W. Lemmon "Fundamental Equations of State for Parahydrogen, Normal Hydrogen and Orthohydrogen" in Journal of Physical and Chemical Reference Data 38, 2009

[9] E. Rothuizen, W. Merida, M. Rokni, and M. Wistoft-Ibsen "Optimization of hydrogen vehicle refueling via dynamic simulation" in International Journal of Hydrogen Energy, 2013

[10] D. Shaw, J. Yu and C. Chieh "Design of a Hydraulic Motor System Driven by Compressed Air" in Energies, 2013

[11] M. Simon "Pneumatic Vehicle, Research and Design" in Procedia Engineering 181, 2017

[12] D. Stolten "Hydrogen and Fuel Cells", Wiley VCH Verlag GmbH and Co KGaA, 2010

[13] V. Tietze and D. Stolten „Comparison of hydrogen and methane storage by means of a thermodynamic analysis" in International Journal of Hydrogen, 2015

[14] J. D. van de Ven and P. Y. Li "Liquid piston gas compression" in Applied Energy 86, 2009

[15] J. Zheng, J. Guo, J. Yang, Y. Zhao, X. Pan, J. Ma and L. Zhang "Experimental and numerical study on temperaturerise within a $70 \mathrm{MPa}$ type III cylinder during fastrefueling'" in International Journal of Hydrogen 38, 2013

[16] EH Group Engineering AG, "Fuel Cell Stack EH51 - User Manual", 2020

[17] Hydrogenics Corporation "HyPM HD 15 Installation and Operation Manual", 2013

[18] M. Klell, H. Eichlseder, and A. Trattner „Wasserstoff in der Fahrzeugtechnik" Springer Vieweg, 2018

[19] T. Schmidt „Wasserstofftechnik“ Carl Hanser Verlag, 2020. 